\title{
Utilization of saffron (Crocus sativus L.) as sensitizer in dye-sensitized solar cells
}

(DSSCs)

\begin{abstract}
Photoelectrodes of dye-sensitized solar cells (DSSCs) have been prepared using nanosized titanium dioxide that have soaked in a solution of different saffron (Crocus sativus L.) spice content in ethanol. The optimized polyacrylonitrile (PAN)-based gel polymer electrolyte with 40.93 wt.\% ethylene carbonate, 37.97 wt.\% propylene carbonate, 4.37 wt.\% tetrapropylammonium iodide, 9.86 wt.\% PAN, 1.24 wt.\% 1-butyl-3-methylimidazolium iodide, $4.35 \mathrm{wt} . \%$ lithium iodide and $1.28 \mathrm{wt} . \%$ iodine has been used as the electrolyte for DSSC. The electrolyte has conductivity of $2.91 \mathrm{mS} \mathrm{cm}-1$ at room temperature $(298 \mathrm{~K})$. DSSCs were also sensitized with saffron solution that has been added with 30 wt.\% chenodeoxycholic acid (CDCA) co-adsorbent and designated as DSSC P4. The solar cell converts light-to-electricity at an efficiency of $0.31 \%$. This is $29 \%$ enhancement in efficiency for the DSSC without addition of CDCA in the saffron-ethanol solution. The DSSC exhibits current density at short-circuit ( $\mathrm{J} \mathrm{sc}$ ) of $1.26 \mathrm{~mA} \mathrm{~cm}-2$, voltage at open circuit ( $\mathrm{V} \mathrm{oc}$ ) of $0.48 \mathrm{~V}$ and $51 \%$ fill factor. DSSC P4 also exhibits the highest incident photon-to-current density of more than $40 \%$ at $340 \mathrm{~nm}$ wavelength.
\end{abstract}

Keyword: Saffron; Crocus sativus L.; Dye-sensitized solar cells; Gel polymer electrolytes 